\title{
Getting out of the swamp? Methodological reflections on using qualitative secondary analysis to develop research design
}

Published in: International Journal of Social Research Methodology

DOI: $10.1080 / 13645579.2016 .1257678$

\begin{abstract}
In recent years, the possibilities and pitfalls of qualitative secondary analysis have been the subject of on-going academic debate, contextualised by the growing availability of qualitative data in digital archives and the increasing interest of funding councils in the value of data re-use. This article contributes to, and extends these methodological discussions, through a critical consideration of how the secondary analysis of thematically related qualitative longitudinal (QL) datasets might be utilised productively in qualitative research design. It outlines the re-use of two datasets available in the Timescapes Archive, that were analysed to develop a primary empirical project exploring processes of continuity and change in the context of men's care responsibilities in low-income families. As well as outlining the process as an exemplar, key affordances and challenges of the approach are considered. Particular emphasis is placed on how a structured exploration of existing QL datasets can enhance research design in studies where there is limited published evidence.
\end{abstract}

Keywords: Qualitative secondary analysis (QSA); qualitative longitudinal data; conceptual frameworks; realist methodology; Timescapes

\section{Introduction}

This article examines the methodological opportunities and challenges that arose when exploring the re-use of existing qualitative longitudinal (QL) datasets to develop a new empirical study. The datasets are currently stored in the Timescapes Archive, a specialist resource of QL data, established in 2012 as part of the ESRC Timescapes Initiative for Qualitative Longitudinal Research (2007-2012). The key aims of the Leverhulme Trust funded 'Men, Poverty and Lifetimes of Care' (MPLC) study reported here were two-fold; (1) to determine the feasibility of using existing qualitative data generated by other researchers to support and potentially enhance the development of a conceptual framework for a new empirical study, and (2) to explore and extend the methodological possibilities afforded by the Archive, one of the key purposes of its creation.

Given the relatively recent establishment and accessibility of the Archive, and its new functionality (Middleton et al., 2014), the possibilities open to new users of the thematically linked datasets remains a relatively unchartered methodological terrain, particularly when working within and across two or more of them. In 2011, a dedicated secondary analysis strand of Timescapes explored key methodological questions relating to the secondary analysis of QL data and this study made notable contributions to existing debates about qualitative secondary analysis (hereafter QSA) more generally (see Irwin, Bornat, \& Winterton, 2012; Irwin \& Winterton, 2011, 2014). Building from this methodological advancement, a key strand of the study reported here sought to explore whether or not QSA could inform, guide and structure the considerable intellectual work that is required in the early phases of research. This inquiry has supported reflection on additional questions addressed in this paper: (1) How feasible, and indeed desirable, is it to conduct secondary data analysis across existing data from 
two (or more) QL studies? and (2) to what extent can this be done to inform qualitative research design?

This article is both an account and a critical reflection on QSA methodology and its potential for 'scaling up' (Neale \& Bishop, 2012 ) and expanding upon established modes of QL research. It begins with a brief explanation of the 'getting out of the swamp' metaphor, as a mechanism for situating the re-use of existing data to develop research design and also for adequately capturing the complexities of the process of developing research. The strategy employed was strongly informed by existing debates about the methodological possibilities and pitfalls of QSA and these debates are reviewed in the next section. I describe the MPLC study and the decisions that were made in conducting the analysis, followed by critical reflection on the extent to which this aided in 'getting out of the swamp' and influenced the development and design of the empirical phase that followed. The article concludes with some final reflections on the questions posed, including considerations of the methodological implications of reusing QL data for the purposes of research design.

\section{'Getting out of the swamp'}

For realist methodologist Emmel (2014), 'getting out of the swamp' is a metaphor that captures the messiness and complexities of the early processes that always precede the empirical work required to tackle a research problem. It symbolises the unique, painstaking and demanding journey that a researcher embarks upon in order to define, understand and frame their study. It is therefore fitting for several reasons. For the researcher, tackling a research problem can often feel like a swamp because at the outset, it is impossible to know its potential width or depth. Researchers not only bring their own presuppositions, ideas and theories to a research problem but they also engage with and draw upon the ideas and theories of others, before seeking to test and refine these theories with new empirical data. To get to 'higher ground', and to a better view of how a study should be effectively designed and conducted, researchers must also first get through a swamp of 'interpretation and theory building that rely on description, interpretation and explanation from past research' (Emmel, 2014, p. 92).

Considered this way, research designs are acknowledged as 'real entities' with real consequences for how research is actually conducted (Maxwell, 2012) and how theories and explanations are produced.

The processes involved in the early work of tackling a research problem are rarely presented and reflected upon in the academic literature. Instead, research outputs tend to focus on the outcomes of analysis (see Long-Sutehall, Sque, \& Addington-Hall, 2010). Emmel (2014) reflects that this might be a result of the dominance of grounded theory approaches in qualitative research. However, early purposive work always inevitably frames and shapes the choices made in engaging with the empirical work that follows. As an example, researchers will select cases purposefully and strategically on the basis of the causal theories and conceptual concepts that emerge in these early stages (Emmel, 2014). As such, an internally strategic and generative mechanism lies with the researcher. While a researchers' knowledge of the generative mechanisms and feedback loops that inform their approach and their choices can only ever be partial, it is increasingly expected that reflexive researchers should go as far as possible to disclose and interpret the ways in which they explain social processes (Emmel, 2014 ). Maxwell (2013) argues that in realist research, there should be no rules or constraints about what sources can be used to construct the conceptual framework for a study. In 
all research, the conceptual framework is significant because analytical strategies depend on it as the epistemological, theoretical and methodological glue that holds a study together (Neale, 2011). For the majority of researchers the conceptual framework is typically represented by a literature review, usually in narrative form, where the theories and interpretations of prior research that are of relevance to the research problem are selected and presented (Maxwell, 2013; Emmel, 2014). The question of whether it is possible, or even desirable, to re-use raw data from past research as an additional source of inspiration within this process, has yet to be fully considered. In the example focused on in this paper, the re-use of existing data was conducted with the intention of opening up methodological questions and developing a conceptual framework, but has also had the additional benefit of showcasing and extending the scope of existing data that is of relevance to a topic that is currently under-researched and where a lack of evidence has been identified (Bennett \& Daly, 2014; Ridge, 2009). In the language of realism, it has therefore become a key generative and structural mechanism, exerting liabilities on the empirical phase that followed. As a result, secondary analysis has been a key driver of the process of journeying through, and eventually emerging from 'the swamp' during the early stages of the MPLC study.

In agreement with Greenhalgh's (2008) observation (referenced by Emmel, 2014), the process has been uniquely time-consuming, frustrating and unpredictable. Several stages of analysis and familiarisation were required to develop the research frame, including the identification of relevant datasets: building relationships with members of both primary research teams to negotiate access: choosing the most appropriate cases to work with from each of the datasets: a process of determining the most effective ways of analysing both within and across datasets: and finally more reflexive considerations of the extent to which the process of secondary analysis itself shaped the empirical project that followed and took it in a productive direction. Despite the amount of work required, charting the various strategies that were employed to negotiate what at times seemed like an additional swamp of data, theories and stakeholders, has highlighted the key challenges and affordances of re-using data in this way. It is the progression of this analytical journey that the remainder of the article reports upon.

\section{Re-using qualitative data: the possibilities and pitfalls}

In this study, the decision to access and analyse several existing QL datasets from the archive was purposeful and was built into the funding proposal with support of one of the original Timescapes research team members. This design supported exploration of methodological, as well as substantive questions. The decision to conduct QSA as a distinct phase of the research was also dependent on a familiarity with the existing literature developed during previous research, which confirmed the lack of evidence in this area of substantive interest.

The Following Young Fathers (FYF) and Intergenerational Exchange (IGE) datasets were identified at this initial stage 2 for their substantive relevance. The process of understanding the methodological implications of QSA began when funding was obtained. To ensure a rigorous approach, initial engagement with existing debates about the methods of QL analysis, including as a secondary analyst was deemed essential. These debates have been framed predominantly in terms of the prospects and dangers of such an approach although the initial polarisation that characterised these early engagements, has been replaced with more nuanced reflection in recent years. 
Compared to the well-established tradition of re-using quantitative data (Long-Sutehall et al., 2010), the secondary analysis of qualitative data is relatively recent. In the last decade however, a culture of archiving and 'data-sharing' has emerged (Coltart, Henwood, \& Shirani, 2012), providing researchers with greater opportunities to explore and extend the reach of qualitative data. According to Irwin and Winterton $(2011$, p. 2) secondary analysis broadly refers to the re-use of data produced for prior purposes in order to 'glean new social scientific and/or methodological understandings'.

Reflecting methodological diversity in this regard, data has already been re-purposed in numerous ways, including when researchers have sought to: assess the credibility or generalizability of small studies; to generate rich descriptive information; to reveal new methodological insights; to generate new findings from analysing 'old' data from a new research context; and to gain insights into sensitive topics or elusive and hard-to-reach populations (see Irwin \& Winterton, 2011; Long-Sutehall et al.,

2010 for a review of relevant studies). Hinds, Vogel, and Clarke-Steffen (1997) and Bishop (2007) also suggest that secondary analysis might be used to pursue interests that are different to those of the original analysis.

More recently, there have been attempts to explore the methodological affordances of working within and across several datasets. Gray, Geraghty, and Ralph (2013) for example, gleaned insights about change and continuity in Irish familial and intergenerational relationships between grandchildren and their grandparents across four birth cohorts through the re-use of two major qualitative datasets from the Irish Qualitative Data Archive. Irwin et al. (2012) and Irwin and Winterton (2014) also present various analytical strategies for working within and across several of the Timescapes datasets as exemplars of what might be achieved. Their strategy included longitudinal case base analysis and the translation of concepts and evidence across research projects to enable meaningful analytic conversation. With Ros Edwards and Lynn Jamieson, Weller and Davidson have also recently launched a feasibility study that explores the possibility of working across all of the Timescapes datasets to develop concepts of care and intimacy.

While the potential and possibilities of QSA are well established in the literature, caution about the method is also evident in both British and international sociology of the last decade (Bornat \& Bytheway, 2012; Broom, Cheshire, \& Emmison, 2009; Coltart et al., 2012; Hammersley, 2010; Heaton, 2004; Irwin et al., 2012; Mauthner, Parry, \& Backett-Milburn, 1998). These debates emphasise the various epistemological and ethical issues that require careful and critical consideration by all analysts. Mauthner et al. (1998) for example, raised early concerns that secondary analysts risk being 'naively realist' if they treat data as foundational, neutral and 'cleansed' of the multiple contexts (contextual, conceptual and interactional) in which they were produced and should be understood (Irwin, 2013). According to Henderson, Holland, McGrellis, Sharpe, and Thomson (2006), interventions such as these were prompted by understandings of the nature of qualitative research in itself. Unlike quantitative data, the researcher-participant relationship is considered a core aspect of the interpretation of qualitative data (Gillies \& Edwards, 2012) and meaning is made, rather than found within the context of research encounters (Henderson et al., 2006). As a counter point, Irwin and Winterton (2012) suggest that while primary analysts do have a privileged relationship to the data generated, this need not end all consideration of re-using data generated by others. 
Other commentators have also questioned the severity of these problems (Hammersley, 2010; Irwin \& Winterton, 2012; Moore, 2007), not least because the challenges associated with re-using data also occur in some kinds of 'primary' research (Hammersley, 2010). This is illustrated by more general concerns about returning to data at a later stage. Primary researchers for example, can never "go back" and reexperience the moment of data collection/production' (Henderson et al., 2006, p. 55); they inevitably re-visit their data after a period of time. For Henderson et al. (2006) this is a problem of researching in time rather than a problem with secondary analysis. The re-analysis of QL data also supports these arguments. As Neale (2011) argues, in terms of their basic analytical principles and processes, there is actually a great deal of overlap between the primary and secondary analysis of QL

data. The flexibility of the QL method provides the freedom for both primary and secondary analysts to rework questions and interrogate data in new ways (Akerstrom, Jacobsson, \& Wasterfors, 2004). In this regard, time is recognised as an irreducible aspect of both data and of the research process in its entirety (Bornat, 2006; Henderson et al., 2006).

In summarising how these debates have developed, Mason (2007) argues that in caricature, the key standpoints represent a moralistic polarisation that potentially obscures complexity and nuance in the arguments for re-using qualitative data. One position argues that qualitative data should not be re-used by others on epistemological and ethical grounds. The other position is more pragmatic, suggesting that data should be re-used, not least because they are expensive to produce. The investigative methodology she proposes focuses attention instead, on what can or cannot be achieved when sociologists re-use data, and supports an account of how this might be done carefully, revealingly and reflexively (Mason, 2007). Beyond such positions, debates indicate that QSA is challenging, requiring carefully constructed methodological strategies for tackling it. It is not likely to be an idyllic process and secondary analysts can expect to encounter a multitude of issues, requiring a strategic and structured, but flexible approach. While the actual, not idealised (Bishop, 2007) process of how secondary analysis might be done is increasingly being reported, albeit briefly (Bornat, Bytheway, \& Henwood, 2008; Elliott et al., 2013) and inconsistently, few reflect on it as a key tool in the early reflexive and intellectual work that takes place in the development of qualitative research design (Emmel, 2014). The remainder of this article seeks to redress this omission.

\section{The study and the datasets}

The MPLC study started in October 2014 with a broad substantive aim of investigating men's care responsibilities within low-income families and how these accumulate and change over time. The proposed research questions were as follows:

(1) What are the routine care responsibilities of men in low-income localities and what resources and constraints affect how they 'do' family and care on an everyday basis?

(2) How do culture, gender, class and personal biographies impact on, and give meaning to their experience of caring (giving and receiving) over time and how do these translate within family networks? 
How might current policy and practice solutions be developed to create the conditions in which the various rewards of caregiving by men can flourish, including in economically deprived families?

Engagement with existing research outputs from both the FYF and IGE studies (e.g. Hughes \& Emmel, 2012; Neale \& Davies, 2015; special issue; Neale, Lau Clayton, Davies, \& Ladlow, 2015) indicated that there was potential to begin to investigate these questions and to conduct a second empirical study that would learn from, and build on what had been done before. Points about the original studies that are of significance to the set up of the MPLC project are described in brief below:

Following Young Fathers: explored how and why young fathers (aged 25 years and under) enter into early parenthood; their changing lives over time; and their support needs and experiences. This study built from the baseline study 'Young Lives and Times' (Project 2 of the original Timescapes Programme, conducted between 2010 and 2012), which tracked a cohort of young people, including a subsidiary sample of young fathers. This subsidiary sample, which is available in the Archive, offered a 'critical case' to provide insights into a different aspect of youth, through the inclusion of socioeconomic variance (see Hanna \& Lau Clayton, 2012). Additional funding for the FYF study supported an extension of research with this group of fathers and the development of a composite study and data-set (Neale et al., 2015).

The final FYF data-set comprised thirty-one young fathers in total from one city in the North of England. Nineteen of those thirty-one fathers are identified as living in lowincome families, ten are identified as highly disadvantaged and eight reported some form of involvement with external agencies such as social services, Criminal Justice Agencies or Child and Family Court Advisory and Support Service (CAFCASS; Neale et al., 2015). The provision of this information in research outputs proved useful because it was based upon this knowledge that a sub-sample of ten transcripts were selected for the purposes of secondary analysis. The ten cases chosen included those men who had been involved in the original 'Young Lives and Times' study, reported some service involvement and were identified as white, marginalised and from lowincome families.

Intergenerational Exchange: developed case studies with eight, hard-to-reach, mid-life grandparents through life histories, family 'maps' and in-depth interviews, tracking the lives of the grandparents and their identified significant others, living on a socially excluded estate in the same city where the FYF study took place. In this study, four sweeps of data collection were conducted with each family between 2007 and 2009, finishing a year prior to the interviews with young fathers in the FYF study. Heritage data from a previous study was also available in some cases ${ }^{4}$. Because grandmothers mainly headed these families, these women were the main focus of the research. In three cases however, the grandfathers were present and contributed to discussion. Across the remaining cases, men of various generational positions moved in and out of the interview settings so that the interviews at times represented impromptu versions of family group interviews (MacLean \& Harden, 2014). This, and the use of casing methods (Emmel \& Hughes, 2008) provided additional glimpses into the experiences of the younger generations of men in these low-income families, men of the same familial generation interviewed in the FYF study. The overall aims of the IGE study were similar to FYF, although IGE was more focused on theorising poverty and 
experiences of socially excluded place than FYF. IGE investigated how vulnerable and marginalised grandparents provide support and care for their grandchildren; sought to address the processes through which poverty is perpetuated intergenerationally; and explored the formal and informal support need of these families. The specific research questions addressed by the project are stated in study outputs (Hughes \& Emmel, 2012).

\section{Bringing the datasets into conversation}

Following this process of familiarisation, it was determined that bringing these datasets into analytical conversation would be both possible and fruitful. Individual conversations with the primary research teams and collective discussion at a datasharing workshop, supported reflection on what the datasets might open up and allow both substantively and methodologically. This process also confirmed that there were distinct parallels in the interpretive frames of both research teams; that there was sufficient thematic linkage between studies; that the studies were synchronic i.e. conducted in contemporaneous times (overlapping the global economic recession in 2008 and the imposition of political austerity in the UK); and that the methodological approaches and choice of methods to generate data in each study were comparable. Both studies employed semi-structured interviews as their main method of research but did so alongside complementary visual and mapping exercises.

Ensuring that the analysis would build upon and extend interpretations produced by the original research teams, together the datasets incorporate the views and experiences of different familial generational groups (parents and grandparents) in comparable lowincome families of the same northern English city, something that neither of the original research teams did systematically. Multiple perspective and intergenerational approaches are not uncommon in qualitative research with families (Harden, BackettMillburn, Hill, \& MacLean, 2010). While challenging (Harden et al., 2010), the complementarity of the datasets meant that different forms of data could be analysed within a common analytical frame. This aided in the development and refinement of the research methodology and supported initial exploration of the extant data.

\section{The process and procedures for analysing the data}

The first stage of analysis involved the selection, management and organisation of data from both datasets (see Tarrant, 2016 for further detail on the practical management of the data). This process was supported by on-going discussions with the primary research teams, an approach characterising reflective borrowing and informed by the 'stakeholder ethics' model (Neale, 2013). These conversations were advantageous because they provided insights into the proximate contexts of data production; confirmed that both datasets could provide relevant substantive evidence; and acquisition of the knowledge that the primary research teams had built up over time as the original data producers, but had not written up in publications. The primary research teams also helped to determine which sub-samples and cases were likely to be most relevant for the study, although I was mindful that such

choices can be emotionally driven (Yow5, 1997) and influenced by the way the primary research teams conceptualise particular themes. This further facilitated the process of making in-roads into what are large, rich datasets and also confirmed that the research questions posed had the potential to take analysis in a productive direction.

An intellectual process of generating insights and findings followed the management and organisation stage, using case histories and framework analysis, which supported 
both thematic and longitudinal readings of the data. There is not the space in this article to fully elaborate on the substantive findings from this analysis but distinct themes were identifiable both within and across the datasets, which enabled consideration of complementarity as well as contrast. These themes were organised around the domains of care responsibilities, employment/education and income, and engagement with services, broadly conceived. As an example, across both datasets men gave examples of being there for family members and described their transitions into care roles as positive and even transformative. Such claims were variously supported, and occasionally undermined, by other reflections on caring practices and lived experience. However, in general these narratives were quite at odds with broader. popular, media and policy discourse that are individualising and construct men as either 'feckless' or entirely absent. The following quotes illustrate the various ways the men talked about the kinds of positive transformations that becoming a father and grandfather engendered, albeit articulated differently from different generational perspectives:

It's changed my personality and who I am and that. I mean I used to be a right little ... but yeah I've, it's made me realise that I need to do good and that and try and stay out of trouble and, so yeah.

Callum,6 age 19, father of twins (FYF)

Well, I always say that having grandkids gives you a second chance at life, you know what I mean cos you've learned by your mistakes ... Cos when you first get married, you get kids, hey there is no manual you know, saying do this do that. You've got to learn by your mistakes, haven't you?

Bob, age 56, grandfather (IGE)

The desire to 'be there' for children and grandchildren reflects broader intergenerational changes in cultural understandings of fatherhood (Miller \& Dermott, 2015) and of the redemptive quality of care provision. However, the reality of doing so in these lowincome families as young fathers and mid-life grandfathers was often much more complicated and such narratives were articulated cumulatively across waves. Common across the IGE and FYF cases were persistent experiences of constraint and lack of choice, which limited possibilities for more variable life course trajectories that might move people out of low-income life. Analyses of these experiences showed that, while the young fathers had aspirations for transitioning into employment, education or training this was not always achievable in the context of balancing the demands of work/education and caring responsibilities. Remarkable similarities were also observable in the men's trajectories in IGE, suggesting that such processes are also relatively enduring in nature. For the older men, the need to balance employment and care responsibilities for several family members was often difficult to manage and influenced whether or not they could gain, or remain in employment over time and consequently who they considered themselves responsible for.

Both studies also explored how formal and informal services intervened in the men's lives in a number of ways. Interventions by specific professionals played a key role in affecting change over time, mediating alternative life trajectories and contouring men's narratives and expectations about care provision. In the language of realism, such interventions could be viewed as examples of what works for these men, in what circumstances, and when (Pawson, 2002). In the right circumstances, men of both generations valued professional involvement, particularly when supported to view their 
responsibilities positively, rather than as personal failings.

Analysis across both datasets also revealed unexpected factors of significance. Recent research about poverty for example has identified a 'disposability of ties' (Desmond, 2012) in which individuals on a low-income form fleeting yet highly resourceful ties with new acquaintances. Yet analysis within and across cases in these studies indicated the significance of men's wider interdependencies in their perceptions and practices of providing care and being cared for over the life course. In particular, both studies evidenced the importance of their relational networks and the hidden care practices and masculinities enacted within intra- as well as intergenerational ties with brothers, fathers, grandfathers and uncles. Overall, it has also been possible to hypothesise that in contexts of limited capital (cultural, economic and social), the intersections of marginalisation, masculinity and social exclusion intersect to produce specific care arrangements over time (such as kinship carer headed households and intragenerational configurations of care), producing a more nuanced picture of men's absence and/or presence in these families and the consequences of this for different generations.

\section{Challenges of working with the datasets}

The re-use of existing QL data was certainly challenging and time-consuming and highlighted key issues when working with data that was generated by other researchers, that is orientated to time and with men from comparable socio-economic circumstances, but of different familial generations.

One major issue at the outset was working with large volumes of data from two differently orientated projects. As Lewis (2007, p. 550) has argued the sheer volume of data 'is at once the delight and challenge of qualitative longitudinal analysis' and as a secondary analyst familiarising myself with two different and unfamiliar sets of data, this initial stage created a swamp of evidence, that was daunting despite having received advice and support from the primary research teams. Pettigrew (1995, p. 111) has also used metaphors that resonate with the notion of a swamp, warning of 'death by data asphyxiation: the slow and inexorable sinking into the swimming pool that started so cool, clear and inviting and now has become a clinging mass of maple syrup'.

Multiple readings of the data were required in order to analyse continuity and change, so the lack of familiarity with each case, added to the complexity of an already complicated task. A great deal of time had to be committed to reading and re-reading, just to become acquainted with each individual case. The more of the transcripts and accompanying metadata7 I read however, the easier it became to select appropriate cases and to identify emerging themes and processes, first within individual case histories and then shared across datasets. The process was also guided by the research questions that I was seeking to refine, including the concepts underpinning them. Consequently, the search for evidence was not an unstructured exploration. The development of shared themes supported the translation of evidence across datasets both to compare and contrast the experiences of each generation of men and to explore men's care responsibilities within generations and across the life course.

Another issue that arose during the analysis phase was that specific issues that were raised by both generations of men were not followed up by the original research teams or explored in depth across datasets. In both datasets for example, in the process of reflecting on the long-term financial implications of having children in relationships that had broken down, the fathers raised concerns about child support payments. In the 
quotes below, both men reflect on the problematic ways in which child support payments construct them purely as financial providers, rather than men who desire to be involved intimately with their children (Dominic) or with additional care responsibilities within new sets of relationalities (Victor). This highlights the complex range of non-material reasons behind their (un)willingness to pay child support (Natalier \& Hewitt, 2010):

At the moment [ex-partner] hasn't approached me for maintenance, which I feel ... once she either goes into

full time work or if she goes ... to university or whatever ... I think she's going to approach me. I can't imagine

why she wouldn't ... it seems to be in her favour to get money outta me. Which, is very annoying when I've been

forced into this predicament and on top of it, I'm being told 'you're paying this money'. It's like 'well I'll have

him full time' [laughs]

Dominic, age 19, separated, works full time (FYF)

... from when I left my ex, I was paying her maintenance, but she was refusing to let me see [son from previous relationship] ... my ex partner, she's never worked and she's always sat on benefits, which then affected what happened to me, then, with the Child Support Agency ... What she did was, she took two part time jobs, the emphasis then was on me ... they weren't legal jobs. The emphasis was then on me to grass her up for working on the side whilst at the same time being pursued for maintenance by the Child Support Agency. I couldn't convince them, because they saw me just as an absent father, who was disgruntled and would say anything, and, erm, the Child Support Agency, although I had four step-children, dismissed [names of step-children with Carolyn] and said that they, and they actually wrote to us ... They said, 'They do not count, you are an absent parent'. It meant

Carolyn was worse off and her children were worse off than before I moved in, and I thought that was intolerable.

Victor, age 44, re-partnered father (IGE)

Given the differing focus of each study and their longitudinal designs, the issue of child maintenance, as a factor in determining men's specifically gendered experiences of poverty was not explored much further by the primary research teams because other issues and themes often took precedence.

As a man in the IGE study, Victor was not questioned much further on the current circumstances of his relationship with his ex-partner and his son, as the research focus was on his relationship to his grandchild. This left a significant gap in the evidence for my own purposes, providing only a partial understanding of the changing circumstances of these relationships and the biographical context that had produced this narrative. This was an issue in the IGE study more generally. Another of the

grandfathers for example, stopped engaging in the study altogether because he felt that it was more focused on the experiences of the grandmothers. The research focus therefore limited the availability of data generated with the men themselves. Nonetheless, prompted by these analytical discoveries, child maintenance is being explored more explicitly in the follow on study to better understand issues of gender, 
power and responsibility across households, from the perspective of low-income men.

\section{Affordances of the approach}

Despite the challenges of working with a large amount of unfamiliar data and the timeconsuming nature of engaging in multiple readings of both datasets in order to start to generate some findings, the process of analyzing existing datasets has been a fruitful and productive way of developing the conceptual framework and study design for the MPLC study, with real consequences for its conduct. Operating as a distinct analytical phase in the research, it has played a significant role in generating empirical findings from the extant data; refining the original research questions; and also generating access to the field.

It has been difficult to develop strong substantive conclusions using this evidence. Nonetheless, new insights emerging from bringing these existing studies together have been identified, including the specifically gendered processes that influence men's longitudinal risks of poverty and consequently, their situation in wider family configurations over time and across the life course. The identification of these processes, which were undeveloped in both of the existing datasets, means that apparent dead ends in the existing data such as child maintenance and the significance of men's wider familial networks have become opportunities for further exploration. These themes, including men's interdependencies with other generations of men and the economic factors contributing to men's poverty (like child maintenance), have been built directly into the design of the semi-structured interview schedules for the next empirical phase of the study. It has also been possible to identify longitudinal commonalities in these men's lives and their affects at different stages of the life course, in order to understand the interplay between their personal experiences, their unfolding trajectories and broader social and historical contexts. While they share normative narratives of 'being there' for their families, their long-term, precarious financial situations; tenuous relationship to the labour market; and personal biographies uniquely shape their care responsibilities and practices over time. There is still scope therefore to explore these complexities and to ask new questions in the follow on study.

Despite experiencing a deluge of data earlier in the process, reaching this stage of clarification felt like the beginning of the emergence from the swamp. Common themes had been identified and I had begun to refine the research questions and underpinning concepts. For example, in my analytical focus I shifted from the language of care to caring; introduced more emphasis on responsibilities; and identified the existence of broader masculine relational networks through which men negotiated meanings of care, support with their caring, and other benefits. These were developed as themes throughout the course of analysis that I then began to translate across datasets. The productive relationships I developed with the primary research teams also provided a starting point for sampling and the recruitment of participants based on their existing relationships of trust with gatekeepers. Using contacts from these original studies, it was possible to build strong relationships with formal and charitable service providers in the localities. These individuals became gatekeepers to the MPLC study, offering their perspectives on men's trajectories. I also brought some of these individuals together at a stakeholder meeting to act as key-informants, using excerpts of data from both datasets to stimulate discussion and reflection on what they observe are key issues for men in low-income families. These reflections were also built into the research 
design, which was co-produced.

Unlike the IGE team, the FYF research team did not keep specific access records for their participants. However, discussions with them, readings of project outputs and analysis of their transcripts, highlighted the importance of their relationships with service providers to recruit their participants. In becoming affiliated with the FYF study it was possible to engage directly with their gatekeepers. One of these has since agreed to contact original participants from FYF and they have now been interviewed for the MPLC study. Collaboration with both teams has therefore also shaped and strengthened an ongoing impact agenda for the research.

\section{Conclusions - emerging from the swamp?}

This article has outlined the process of analysing two existing QL datasets from the Timescapes Archive to productively inform research design, a process that has been likened to 'getting out of the swamp'. Such an approach represents an expansion of established models of QL research through the re-use of several existing datasets. In particular, new methodological questions that have yet to be considered within existing debates about QSA have been deliberated. These include: (1) How feasible is it to conduct secondary data analysis across existing data from several QL studies? and (2) to what extent can this inform qualitative research design? In outlining the affordances and challenges of the reflexive and intellectual process of 'getting out of the swamp', the article offers a worked example of how this can be achieved.

The re-use of qualitative data for this purpose certainly required time commitment and attention to the multiple contexts of data generation. However, while engagements with what felt like a deluge of unfamiliar data at the outset, made the process of developing the research study seem distinctly muddy in the early stages, the process has been both productive and feasible. In particular the use of secondary analysis has aided in the development and refinement of an alternative research methodology that has influenced the ongoing research. As a distinct phase of the research process, it has aided in the generation of a conceptual framework; in identifying new and specific analytical directions; and the generation of additional insights from existing studies, contributing to a knowledge base where evidence is limited. Overall, progress through the swamp of data and the ongoing dialogue between the extant published research and empirical inquiry, was effective because it was structured by a distinct methodological strategy and was organised in relation to specific research questions that I sought to refine and develop.

The re-use of the datasets has also played a key role in informing the research design of the follow on study, influencing its conduct. Access to the data has aided in directing the research focus and the identification of specific lines of enquiry relevant to research with men living on a low-income in this particular city, issues that were not followed up in the original studies. Engagement with the primary research teams also informed access methods to men living on a low-income in the city of study and supported the opportunity to extend the longitudinal research of the existing studies. In these myriad ways, the re-use of the datasets has certainly been both feasible and productive, indicating that the secondary analysis of QL data, including of more than one data-set, has much to offer, both methodologically and substantively.

Notes

1. The archive acts as a bespoke repository for primary researchers by facilitating their 
on-going analysis, and also brings related datasets, with shared substantive interests in family, relationships, identities and time, together, for enhanced analysis by both primary and secondary users (Neale \& Bishop, 2012).

2. The bid was positioned specifically so that it could build out of, and extend, the existing secondary analysis work conducted as part of Timescapes. Choices of dataset were therefore limited to Timescapes in this instance, although there is a wealth of qualitative data archived elsewhere that might have relevance to this particular study. Qualidata UK is just one example where archived data might be accessed for similar purposes.

4. The heritage data was generated for methodological research carried out between 2003 and 2005, that sought to identify methodologies for accessing individuals and groups considered hard to reach (see Emmel \& Hughes, 2012).

5. When a colleague questioned why Yow didn't write about her participants' race prejudice she wondered if it was because she liked them too much. In being asked to choose transcripts, it is likely that primary researchers will also be influenced by their interactions with participants and the emotions they associate with them. If working directly with primary research teams it is important for secondary analysts to be aware of this and to consider how this might influence their own sampling choices.

6. All names used throughout the article are pseudonyms assigned to participants by the primary research teams to protect their privacy and that of their families.

7. While there was some inevitable variation, for both studies metadata was available in the form of pen portraits for each wave for each participant, sample data, copies of interview schedules and field notes written by the primary research teams.

\section{Acknowledgements}

Thank you to the primary research teams of FYF and IGE for being so generous with their time and data. Thanks also to

Sarah Irwin and Kahryn Hughes for their comments on earlier drafts of this manuscript and to the anonymous reviewers.

\section{Disclosure statement}

No potential conflict of interest was reported by the author.

\section{Notes on contributor}

Anna Tarrant is currently a Leverhulme Trust Early Career Fellow at the University of Leeds and is exploring men's care trajectories in low-income localities. Prior to this she worked on a number of research projects that have developed her research expertise in men and masculinities, grandparenting, and informal care and family practices. She has published articles in Sociology and Men and Masculinities about her research on contemporary grandfathering and has edited a small collection about ageing masculinities, published in collaboration with the Centre for Ageing and Biographical Studies (Open University) and the Centre for Policy on Ageing (CPA).

\section{References}

Akerstrom, M., Jacobsson, K., \& Wasterfors, D. (2004). Re-analysis of previously collected material. In C. Seale, S. Silverman, J. F. Gubrium, \& G. Gobo (Eds.), Qualitative research practice (pp. 314-327). London: Sage.

Bennett, K., \& Daly, M. (2014). Poverty through a gender lens: Evidence and policy 
review on gender and poverty. York: Joseph Rowntree Foundation.

Bishop, L. (2007). A reflexive account of reusing qualitative data: Beyond primary/secondary dualism. Sociological Research Online, 12(3). Retrieved from http://www.socresonline.org.uk/12/3/2.html

Bornat, J. (2006). Secondary analysis of one's own and others' data. Paper given at: Practice and Ethics in Qualitative Longitudinal Research, ESRC seminar, University of Leeds, Leeds.

Bornat, J., \& Bytheway, B. (2012). Working with different temporalities: Archived life history interviews and diaries. International Journal of Social Research Methodology, 15, 291-299.

Bornat, J., Bytheway, B., \& Henwood, K. (2008). Report of meeting between Timescapes' 'Men as Fathers' and 'The Oldest Generation' projects: University of Cardiff, 21st July 2008. Retrieved from http://www.timescapes.leeds.ac.uk/assets/ files/report-fathers-oldest-generation-projects-july08.pdf

Broom, A., Cheshire, L., \& Emmison, M. (2009). Qualitative researchers' understandings of their practice and the implications for data archiving and sharing. Sociology, 43, 1163-1180.

Coltart, C., Henwood, K., \& Shirani, F. (2012). Qualitative secondary analysis in austere times: Ethical, professional and methodological considerations. Forum: Qualitative Social Research, 14, 18. Retrieved from http://www.qualitativeresearch. net/index.php/fqs

Desmond, M. (2012). Disposable ties and the urban poor. American Journal of Sociology, 117, 1295-1335.

Elliott, H., Brannen, J., Phoenix, A., Barlow, A., Morris, P., Smart, C., ... Bauer, E. (2013). Analysing qualitative data in groups: Process and practice (NOVELLA Working Paper: Narrative Research in Action: Thomas Coram Research

Unit). Retrieved from http://eprints.ncrm.ac.uk/3172/1/jointanalysispaper200813.pdf

Emmel, N. (2014). Sampling and choosing cases in qualitative research. London: Sage. Emmel, N., \& Hughes, K. (2008). Small-N access cases to refine theories of social exclusion and individuals and access to socially excluded individuals and groups. In D. Byrne \& C. C. Ragin (Eds.), The SAGE handbook of case-based methods (pp. 318-330). London: Sage.

Emmel, N., \& Hughes, K. (2012). 'Recession, it's all the same to us son': The longitudinal experience (1999-2000) of deprivation. Twenty-first Century Society, 5, $171-181$

Gillies, V., \& Edwards, R. (2012). Working with archived classic family and community studies: Illuminating past and present conventions around acceptable research practice. International Journal of Social Research Methodology, 15, 321-330. 
Gray, J., Geraghty, R., \& Ralph, D. (2013). Young grandchildren and their grandparents: A secondary analysis of continuity and change across four birth cohorts. Families, Relationships and Societies, 2, 289-298.

Greenhalgh, T. (2008). New methodologies for systematic review. Retrieved from www.cochranechildhealth.ualberta.ca/.../Greenhalgh_New\%20Methodologies\%20for $\% 20$ systematic\%20review.pdf

Hammersley, M. (2010). Can we re-use qualitative data via secondary analysis? Notes on some terminological and substantive issues. Sociological Research Online, 15, 5. Retrieved from http://www.socresonline.org.uk/15/1/5.html

Hanna, E., \& Lau-Clayton C. (2012). Capturing past and future time in qualitative longitudinal field enquiry: Timelines and relational maps. Timescapes methods guide series. Retrieved from http://www.timescapes.leeds.ac.uk/assets/files/

methods-guides/timescapes-hanna-capturing-past-and-future.pdf.

Harden, J., Backett-Millburn, K., Hill, M., \& MacLean, A. (2010). Oh, what a tangled web we weave: Experiences of doing 'multiple perspectives' research in families. International Journal of Social Research Methodology, 13, 441-452.

Heaton, J. (2004). Reworking qualitative data. London: Sage.

Henderson, S., Holland, J., McGrellis, S., Sharpe, S., \& Thomson, R. (2006). Inventing adulthoods: A biographical approach to youth transitions. London: Sage.

Hinds, P. S., Vogel, R. J., \& Clarke-Steffen, L. (1997). The possibilities and pitfalls of doing a secondary analysis of a qualitative data set. Qualitative Health Research, 7, $408-424$.

Hughes, K., \& Emmel, N. (2012). Timescapes final report project 6: Intergenerational exchange: Grandparenting and the texture of poverty. Retrieved from http://www.timescapes.leeds.ac.uk/assets/files/Final-Reports/final-report-project-6. pdf

Irwin, S. (2013). Qualitative secondary data analysis: Ethics, epistemology and context. Progress in Development Studies, 13, 295-306.

Irwin, S., Bornat, J., \& Winterton, M. (2012). Timescapes secondary analysis: Comparison, context and working across datasets. Qualitative Research, 12, 68-80.

Irwin, S., \& Winterton, M. (2011). Debates in qualitative secondary analysis: Critical reflections (Timescapes Working Paper No. 4). Retrieved from http://www.timescapes.leeds.ac.uk/assets/files/WP4-March-2011.pdf

Irwin, S., \& Winterton, M. (2012). Qualitative secondary analysis and social explanation. Sociological Research Online, 17, 4. Retrieved from http://www.socresonline.org.uk/17/2/4.html 
Irwin, S., \& Winterton, M. (2014). Gender and work-family conflict: A secondary analysis of Timescapes data. In J. Holland \& R. Edwards (Eds.), Understanding families over time: Research \& policy (pp. 142-160). London: Palgrave

Macmillan.

Lewis, J. (2007). Analysing qualitative longitudinal research in evaluations. Social Policy and Society, 6, 545-556.

Long-Sutehall, T., Sque, M., \& Addington-Hall, J. (2010). Secondary analysis of qualitative data: A valuable method for exploring sensitive issues with an elusive population? Journal of Research in Nursing, 6, 335-344.

MacLean, A., \& Harden, J. (2014). Reflections on researching with children using "family group interviews" as part of a qualitative longitudinal study. International Journal of Child, Youth, and Family Studies, 5, 649-665.

Mason, J. (2007). 'Re-Using' qualitative data: On the merits of investigative epistemology. Sociological Research Online, 12, 3. Retrieved from http://www.socresonline.org.uk/12/3/3.html

Mauthner, N., Parry, O., \& Backett-Milburn, K. (1998). The data are out there, or are they? Implications for archiving and revisiting qualitative data. Sociology, 32, 733745 .

Maxwell, J. (2012). A realist approach for qualitative research. London: Sage.

Maxwell, J. (2013). Qualitative research design: An interactive approach. London: Sage.

Middleton, M. M., Beaman, J., Blyth, G. J., Hughes, K., Neale, B., Phillips, B., ... Salter, J. L. R. (2014). Changing landscapes for the third sector: Enhancing knowledge and informing practice. Report on the Timescapes Archive (Technical Report). Retrieved http://eprints.whiterose.ac.uk/81104/1/CL_Technical_Report_final.pdf.

from

Miller, T., \& Dermott, E. (2015). Contemporary fatherhood: Continuity, change and future. Families, Relationships and Societies, 4, 179-181.

Moore, N. (2007). '(Re)-using Qualitative data?' Sociological Research Online, 12, 1. Retrieved from http://www.socresonline.org.uk/12/3/1.html

Natalier, K., \& Hewitt, B. (2010). 'It's Not Just About the Money': Non-resident fathers. Perspectives on Paying Child Support, 44, 489-505.

Neale, B. (2011). Qualitative longitudinal analysis in social research. Conference Paper. Retrieved from http://www.timescapes.leeds.ac.uk/assets/files/knowledgebank/Neale-Qualitative-Longitudinal-Analysis-in-Social-Research.pdf

Neale, B. (2013). Adding time into the mix: Stakeholder ethics in qualitative longitudinal research. Methodological Innovations Online, 8, 6-20. 
Neale, B., \& Bishop, L. (2012). The Timescapes Archive: A stakeholder approach to archiving qualitative longitudinal data. Qualitative Research, 12, 53-65.

Neale, B., \& Davies, L. (2015). Seeing young fathers in a different way. Families, Relationships and Societies, 4, 309-313.

Neale, B., Lau Clayton, C., Davies, L., \& Ladlow, L. (2015). Researching the lives of young fathers: The following young fathers study and dataset (Briefing Paper No. 8). Retrieved from http://1v9xdi344dkt24du831vqd38. wpengine.netdnacdn. com/files/2015/10/Researching-the-Lives-of-Young-Fathers-updated-Oct-22.pdf

Pawson, R. (2002). Evidence-based policy: The promise of 'Realist Synthesis'. Evaluation, 8, 340-358.

Pettigrew, A. (1995). Longitudinal field research on change: Theory and practice. In G. Huber \& A. Van de Ven (Eds.), Longitudinal field research methods: Studying processes of organisational change (pp. 91-125). London: Sage.

Ridge, T. (2009). Living with poverty: A review of the literature on children's and families' experiences of poverty (Research Report No 594). Department for Work and Pensions. Retrieved from http://www.bris.ac.uk/poverty/downloads/ keyofficialdocuments/Child\%20Poverty\%20lit\%20review\%20DWP.pdf

Tarrant, A. (2016). Qualitative secondary analysis and research design: Reflections on a methodological framework for data re-use. Timescapes Working Paper. Retrieved April 1, 2016, from http://hjh711zvmtv455cla15ikb71.wpengine. netdna-cdn.com/files/2015/07/Working-Paper-QSA.pdf

Yow, V. (1997). “Do I Like Them Too Much?”: Effects of the oral history interview on the interviewer and vice-versa.The Oral History Review, 24, 55-79. 